\title{
Underestimated angle of submarine slope at failure: A short discussion
}

\author{
Bo Chen ${ }^{1}$, Chaoqi Zhu ${ }^{2,1,3,4^{*}}$, Yasheng Feng ${ }^{1}$, Xiaohui Han ${ }^{1}$, Weite Zeng ${ }^{1}$, Congcong Xing ${ }^{5}$, Shili Lin ${ }^{1}$, and Gang Liu ${ }^{1}$ \\ ${ }^{1}$ Hainan Key Laboratory of Marine Geological Resources and Environment, Hainan Marine Geological Survey Academy, 570206, \\ Haikou, China \\ ${ }^{2}$ Laboratory for Marine Geology, Qingdao National Laboratory for Marine Science and Technology, 266061, Qingdao, China \\ ${ }^{3}$ Shandong Provincial Key Laboratory of Marine Environment and Geological Engineering, Ocean University of China, 266100, \\ Qingdao, China \\ ${ }^{4}$ College of Earth Science and Engineering, Shandong University of Science and Technology, 266590, Qingdao, China \\ ${ }^{5}$ North China Sea Environmental Monitoring Center, Ministry of Natural Resources, Qingdao, China
}

\begin{abstract}
Submarine landslides always occur along gently inclined continental slopes, but the reasons for such failure of low-angle submarine slopes are unclear and contentious. A short discussion is presented here to some recent published papers including some inspirations about the low-angle failure of submarine slopes. Because fluid overpressure could lead to steepening slopes before landslide, the inclination of the slopes at failure may be underestimated. We offer a new perspective on low-angle failure of low-permeability slopes.
\end{abstract}

\section{Introduction}

Hance (2003) [1] developed a database of submarine landslides on published literature and 399 submarine landslides in this database are cataloged with slope angle data. The results (Figure 1) show that the 3 to 4 degree slope angle interval has the highest frequency of submarine landslide and that the minimum is 0.22 degree. About 85 percent of these submarine landslides occurred on seafloor slopes flatter than about 10 degrees (Figure 2). Such flat slope angles are much less than for most subaerial landslides. Submarine landslides always occur along gently inclined continental slopes, but the reasons for such failure of low-angle submarine slopes are unclear and contentious.

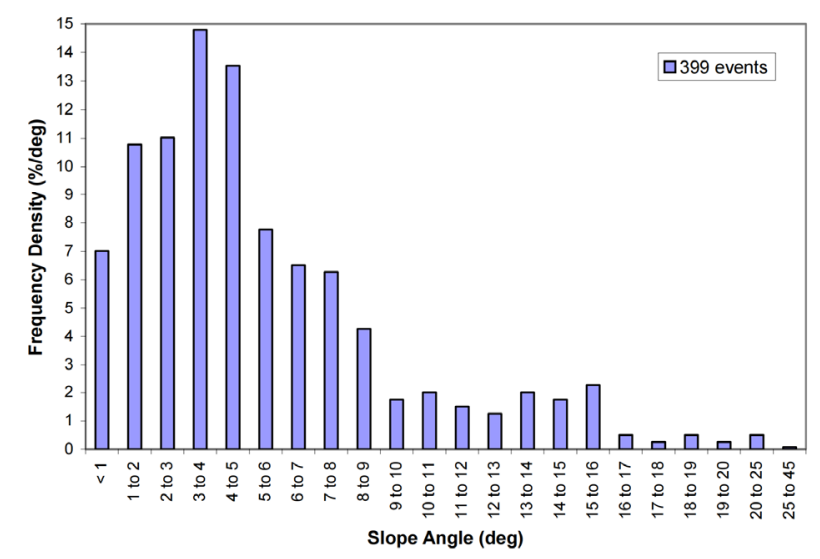

Fig. 1. Frequency density distribution of the average angle of the slope at failure for the seafloor slope failures[1].

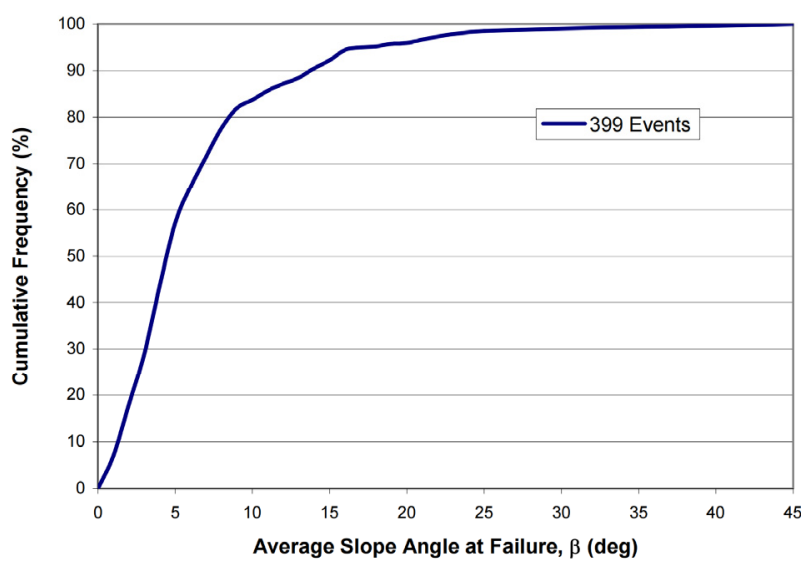

Fig.2 Cumulative frequency distribution of the average angle of the slope at failure for the seafloor slope failures[1].

\section{Discussions}

Submarine slope failures are usually occur on very gentle slopes. The slope angle at failure is usually obtained by determining the average angle of the unfailed adjacent seafloor slope. Without consideration of seafloor evolution before failure, this method may lead to slope angle underestimation.

Yan et al. (2020) [2] have designed a series of new physical model tests to investigate the formation mechanism of pockmark. The gas produced by natural gas hydrate dissociation was simulated by aeration in their experiments. Based on the experimental

\footnotetext{
* Corresponding author: george-zhu@foxmail.com
} 
phenomena, they found some interesting results for the pockmark formation. Though their physical model tests were specifically designed for use in pockmarks, the experimental phenomena (Figure 3) would help to solve unsettled questions about the failure of low-angle submarine slopes. Inspired by Yan et al. (2020) [2] and some recent results, we present the possible reasons for such failure of low-angle submarine slopes.
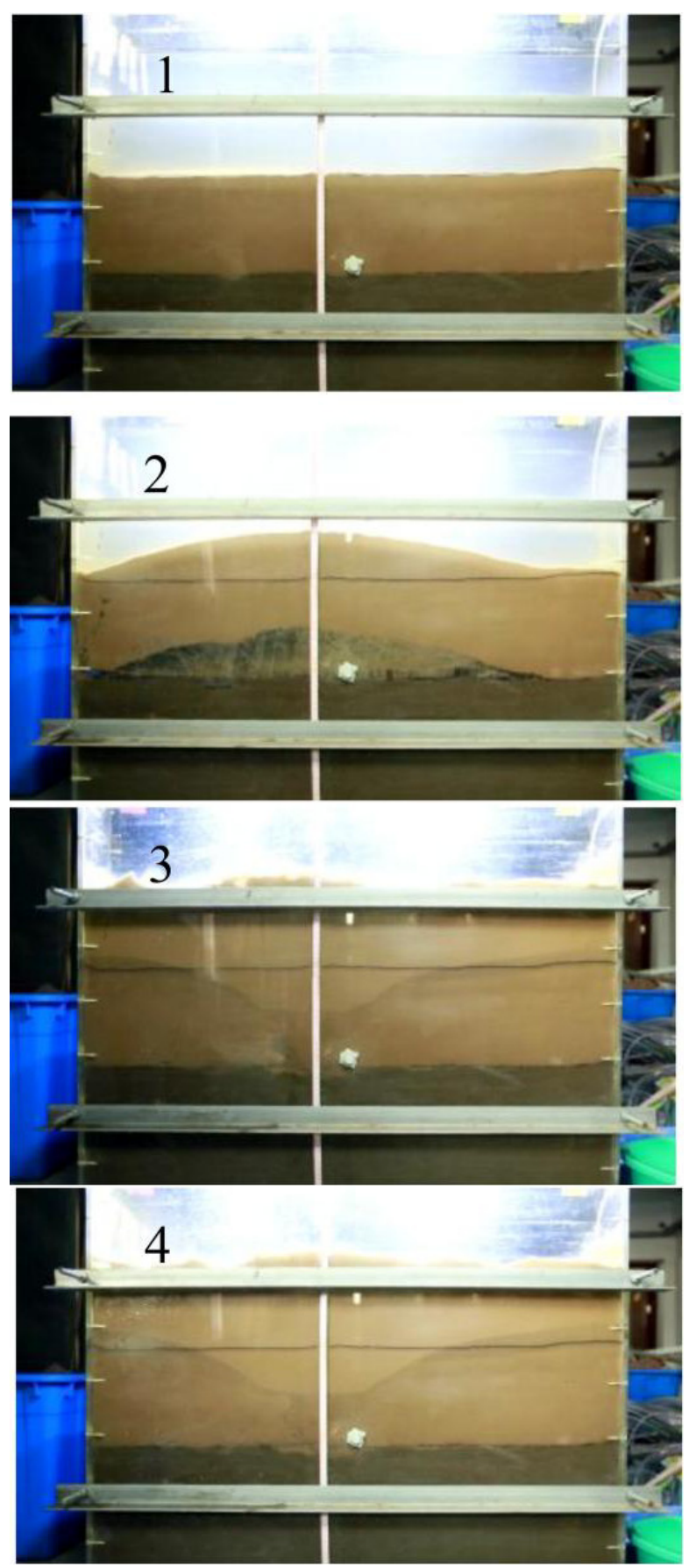

Fig. 3. The experimental phenomena in Yan et al. (2020)

Figure 3 shows that a cavity forms along the interface between the overlying and underlying layers due to aeration. Meanwhile, the clay overlying layer gradually arches upward. Then, pockmark forms after gas eruptions. Such seafloor deformation evolution has been proven by the founding of a cluster of kilometer-wide pockmarks and domes, as well as methane expulsion, in the Barents Sea floor[3]. In Figure 4, Andreassen et al. (2017) [4] proposed a conceptual model that links the domes and pockmarks. Build up of overpressurized gas below the gas hydrate zone leads to formation of a gas hydrate pingo (dome). After gas eruptions, the craters (pockmark) forms. Both the experimental and field results show fluid overpressure leads to steepening slopes before pockmark formation.
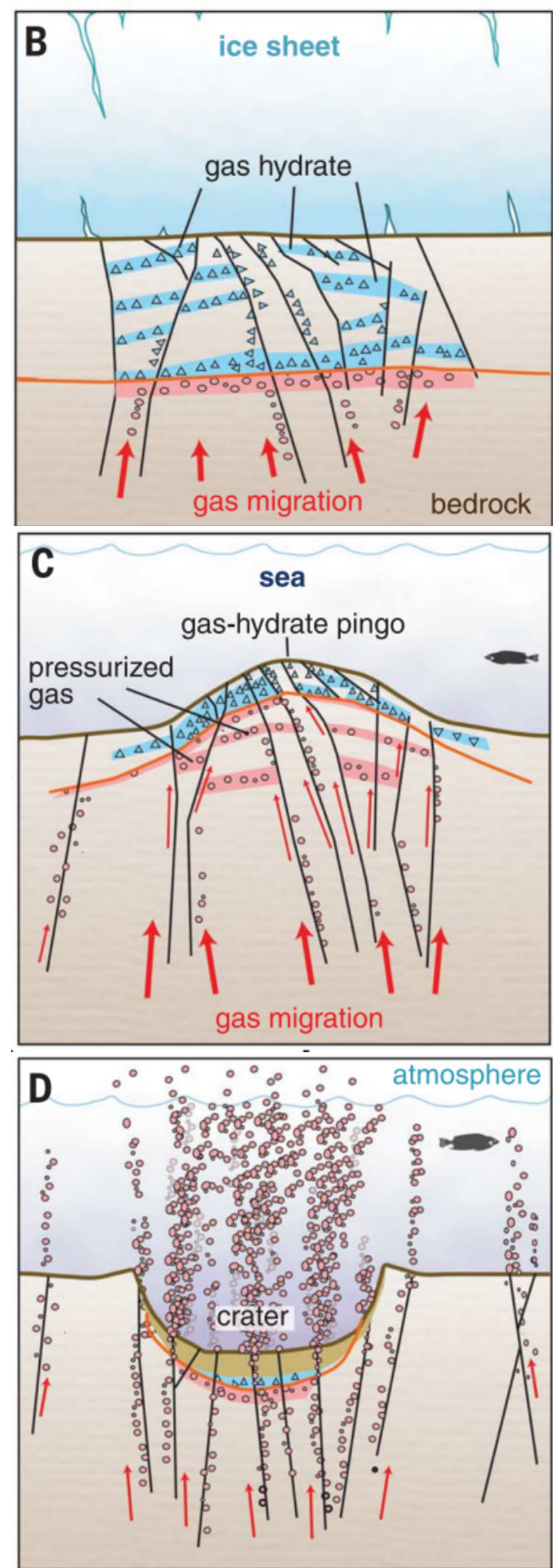


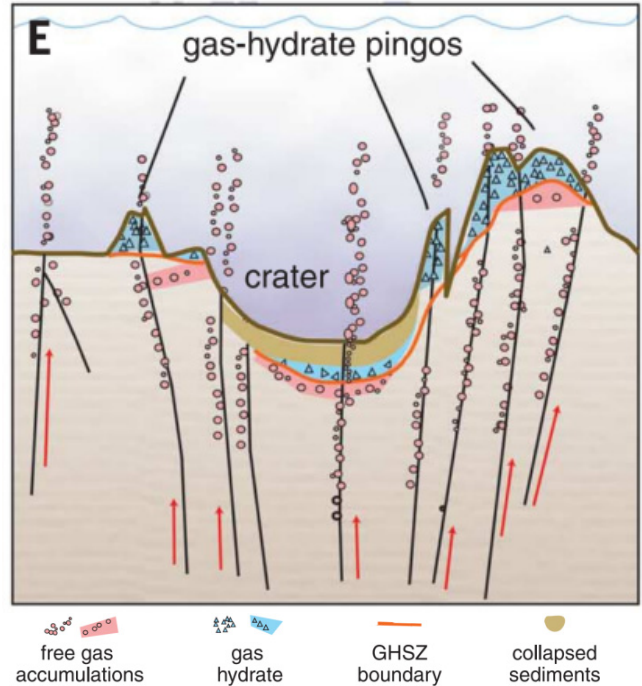

Fig. 4. The conceptual model for pockmark formation in the northern Barents [4]

If the original seafloor in Figure 3 or Figure 4 was inclined at an angle (e.g. $5^{\circ}$ ), the final negative landform could be regarded as a symbol of submarine landslide in a certain sense. Then the angle of submarine slope at failure is estimated as $5^{\circ}$ based on the current method. Because overpressure leads to steepening slopes before landslide, the angle at failure is bigger than $5^{\circ}$. Once the landslide is initiated, the trapped fluid leaks into seawater and the overpressure dissipates. As a result, the steepening slope forms negative landform. The subsequent field survey cannot identify previously tumefied seafloor and steepening slopes. Finally, the inclination of the slopes at failure may be underestimated. Just like Yan et al. (2020) [2], the most recent physical model tests also show the steepening slope due to overpressure [5-6].
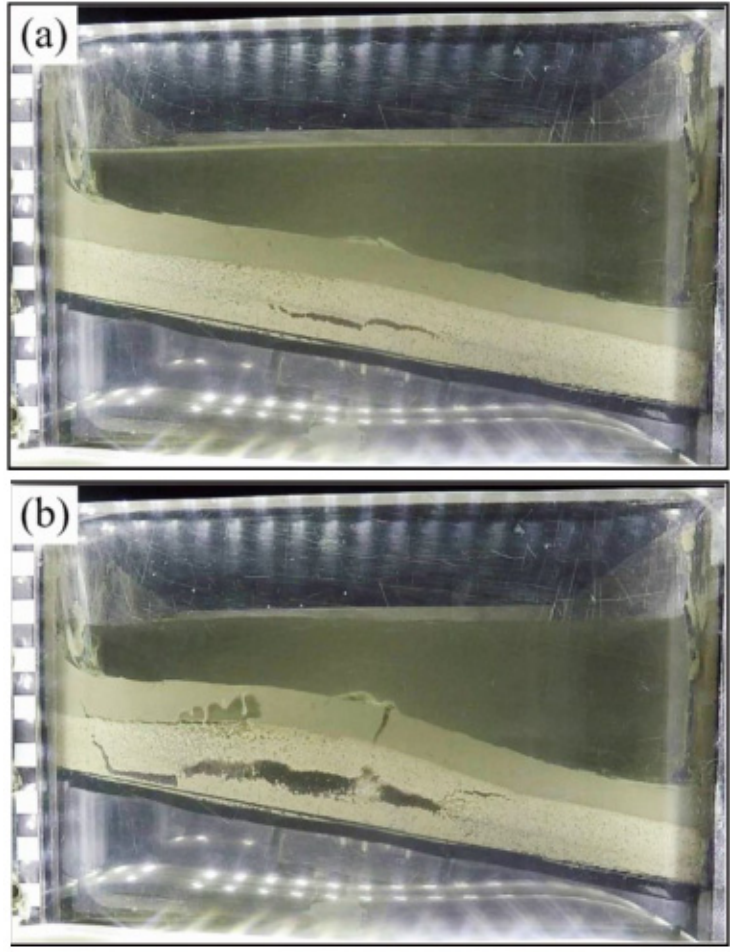
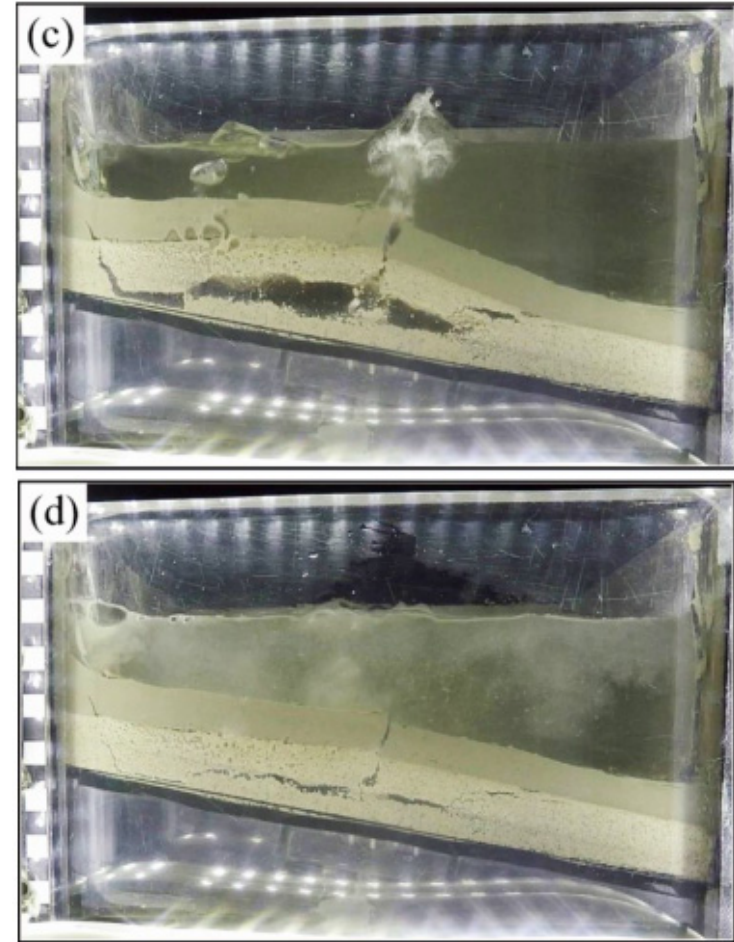

Fig. 5. The experimental phenomena in Nian et al. (2020) [5]

As is shown in Figure 6 or Figure 7, seafloor slope angles evolve over time, and the corresponding landforms become more complex. If ignoring the seafloor deformation evolution before slope failure, the inclination of these slopes at failure may be underestimated.

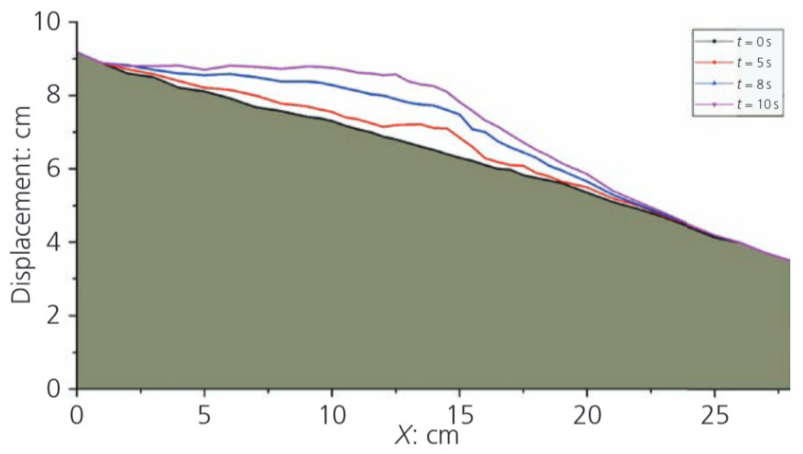

Fig. 6. The slope angle evolution in Nian et al. (2020) [5]

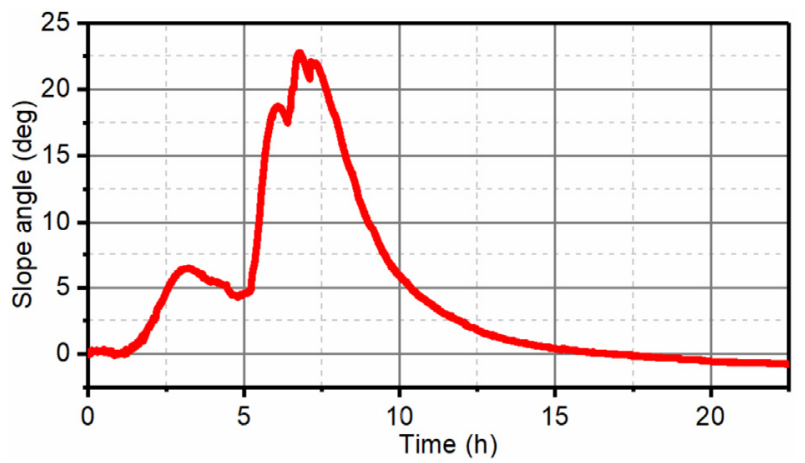

Fig. 7. The slope angle evolution in Zhu et al. (2020) [6] 


\section{Conclusions}

Based on Yan et al. (2020) [2] and some recent results[46 , we propose a new perspective on such low-angle failure of submarine slopes (Figure 8, taking hydrate dissociation for example). If the sediments are finegrained and have a low permeability, excess pore pressures would be generated and act as a loading mechanism on the overlying soil slope. The angle of submarine slope at failure would be underestimated, especially among those with overpressure under lowpermeability overlying layer.

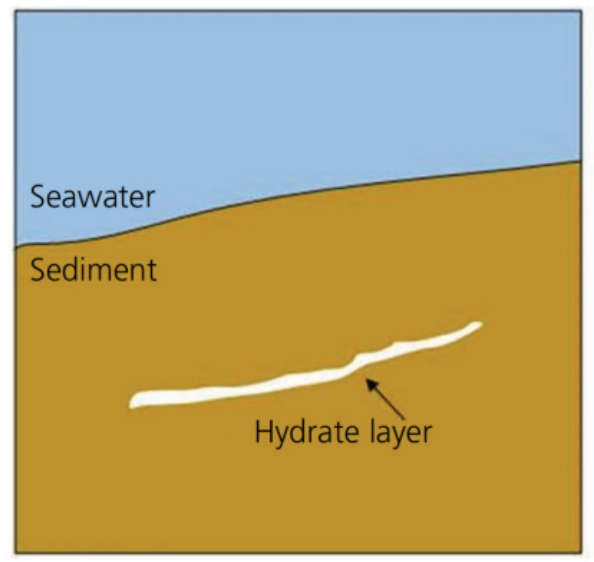

(a)

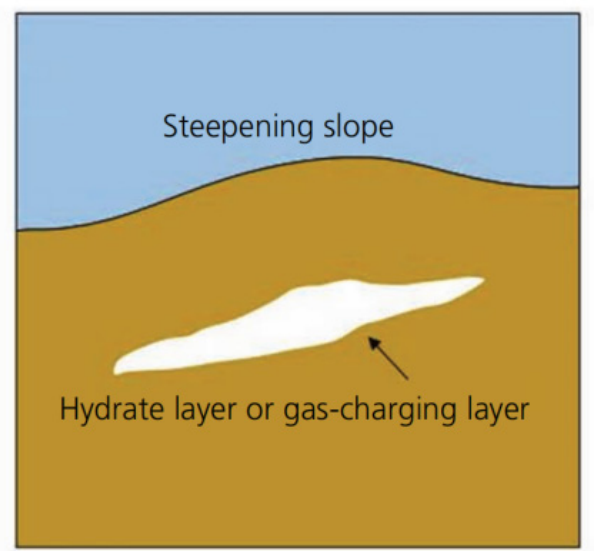

(b)

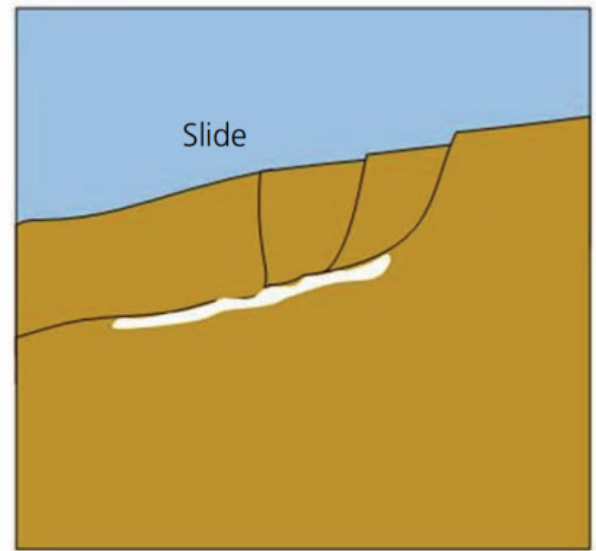

(c)

Fig. 8. Overpressure, steepening slope and submarine landslide during hydrate dissociation (Zhu et al., 2020)[6]
Not all the inclinations of the slopes at failure are underestimated; however, the possibility of angle underestimation cannot be ruled out. Because fluid overpressure leads to steepening slopes before landslide, the inclination of the slopes at failure may be underestimated. We offer a new perspective on lowangle failure of low-permeability slopes.

\section{Acknowledgements:}

This study was sponsored by the Hainan Key Laboratory of Marine Geological Resources and Environment (Grant No. HNHYDZZYHJKF008) and the National Natural Science Foundation of China (Grant No. 41776068).

\section{References}

1. Hance, J. J. (2003). Development of a Database and Assessment of Seafloor Slope Stability Based on Published Literature, The University of Texas at Austin.

2. Yan, X., H. Sun, Z. Chen, F. Shuai, Z. Wei, Y. Xu. 2020. Physical experimental study on the formation mechanism of pockmark by aeration. Marine Georesources \& Geotechnology, 38(3), 322-331. doi: 10.1080/1064119X.2019.1571539

3. Serov, P., S. Vadakkepuliyambatta, J. Mienert, H. Patton, A. Portnov, A. Silyakova, G. Panieri, M.L. Carroll, J. Carroll, K. Andreassen, A. Hubbard. 2017. Postglacial response of Arctic Ocean gas hydrates to climatic amelioration. Proceedings of the National Academy of Sciences, 114(24), 6215-6220. doi: 10.1073/pnas.1619288114

4. Andreassen, K., A. Hubbard, M. Winsborrow, H. Patton, S. Vadakkepuliyambatta, A. Plaza-Faverola, E. Gudlaugsson, P. Serov, A. Deryabin, R. Mattingsdal, J. Mienert, S. Bunz. 2017. Massive blow-out craters formed by hydrate-controlled methane expulsion from the Arctic seafloor. Science, 356(6341), 948-952. doi: 10.1126/science.aal4500

5. Nian, T., X. Song, W. Zhao, H. Jiao, X. Guo. 2020. Submarine Slope Failure Due to Overpressure Fluid Associated with Gas Hydrate Dissociation. Environmental Geotechnics, 2020, doi: 10.1680/jenge. 19.00070

6. Zhu, C., X. Jiao, S. Cheng, Q. Li, K. Liu, H. Shan, C. Li, Y. Jia. 2020. Visualizing fluid migration due to hydrate dissociation: Implications for submarine slides. Environmental Geotechnics. doi: 10.1680/jenge. 19.00068 